\title{
Imagens: documentos de visões de mundo
}

\section{Resumo}

Vivemos em um mundo hipervisual, onde a imagem exerce um papel fundamental de identificação, divulgação ideológica e socialização de significados. Mas por muito tempo a imagem foi negligenciada no contexto dos métodos de pesquisa qualitativa. Nesse sentido, é fundamental que as ciências humanas e sociais reconheçam o potencial das imagens com fins de investigação social, mesmo que a criação delas possa ser caracterizada como uma atividade que exige especialização. A análise de imagens não é uma tarefa simples, de fácil acesso a qualquer pesquisador, pois para ultrapassar o nível imanente de interpretação ou o nível de sentido comum, é necessário o aprofundamento de referenciais teóricos que auxiliem a leitura para além do que ela informa em um primeiro olhar. O presente artigo apresenta um exercício prático de análise de uma fotografia com base no método documentário, cuja origem remonta à Sociologia do Conhecimento de Karl Mannheim. A adaptação do método documentário para a análise de imagens foi desenvolvida por Ralf Bohnsack, que, para tanto, também retomou a teoria da Iconologia de Ervin Panofsky e as contribuições de autores como Max Imdahl e Roland Barthes. Espera-se por meio deste artigo oferecer um contraponto à recorrente crítica em relação à falta de fundamentação teórica, de reflexão, assim como de rigor metodológico no tratamento e na análise dos dados.

\footnotetext{
* Doutora em Sociologia pela Universidade Livre de Berlim/Alemanha. Professora da Faculdade de Educação da Universidade de Brasília e bolsista de produtividade em pesquisa do CNPq. * Doutoranda em Educação na Universidade de Brasília - UnB. Mestre em Educação Brasileira pela Universidade Federal do Ceará - UFC. Professora Assistente I da Universidade do Estado do Pará - UEPA e Professora Adjunta III da Universidade da Amazônia.
} 
Ao mesmo tempo pretende-se incentivar a inclusão de outros tipos de fontes para além do texto/entrevista e da observação, tais como fotografias, imagens e filmes no âmbito das pesquisas qualitativas.

Palavras-chave: Imagem. Fotografia. Análise de imagens. Método documentário. Metodologias qualitativas.

\section{Introdução}

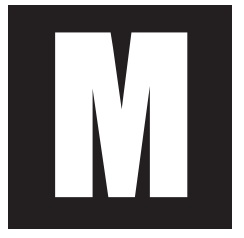

ais do que as palavras, as imagens produzem sentimentos, identificação, favorecem lembranças, disparam a imaginação, a introspecção, entendimentos, anunciam ou denunciam uma realidade, evocam memórias pessoais e visões de mundo. A imagem, apesar de estar presente na história da civilização humana - de constituir os vestígios mais antigos que temos conhecimento, portanto, universais, já que existiram em todas as sociedades -, foi secundarizada ao longo da constituição da ciência, especialmente das ciências humanas e sociais, pois a busca da validade científica deu lugar de prova a documentos escritos (cf. Bohnsack, 2007b e 2010).

Esse movimento dos cientistas e pesquisadores esteve na contramão da organização social, uma vez que o surgimento da escrita não substituiu a imagem no conjunto de códigos de expressão humana, pelo contrário, o visual e o escrito caminharam paralelamente na constituição da cultura dos grupos sociais. É necessário também reconhecer que a imagem é capaz de alcançar grupos sociais com a propriedade que a palavra não tem como atingir. Identificamos, então, na imagem uma dimensão democrática, pois a leitura/escrita, em diferentes momentos históricos, passou 
a ser tarefa de especialistas, ou restrita a pequenos grupos. Enquanto a expressão escrita foi constituindo-se em uma habilidade específica, e de apropriação condicionada, a imagem manteve seu caráter de apropriação individual e coletiva para todos que as tivesse ao seu alcance.

Por outro lado, nas imagens estão implícitos signos e significados, já que, de acordo com o campo da semiologia, devemos considerar que a uma palavra ou seu significado, está associada uma representação, uma imagem mental. Mesmo que consideremos as diferenças culturais como distinções para reconhecimento de significados ou reconhecimento/representação de uma palavra, podemos dizer que há na imagem um caráter mais abrangente de entendimento e significação. Vivemos em um mundo hipervisual, onde a imagem exerce um papel fundamental de identificação, divulgação ideológica e socialização de significados. Nesse sentido, é fundamental que as ciências humanas e sociais reconheçam o potencial das imagens com fins de investigação social, mesmo que a criação delas possa ser caracterizada como uma atividade que exige especialização.

Assim, devemos considerar que a imagem não representa a realidade plasmada em uma superfície amorfa, mas que é constituída e produzida pela realidade social, que é mediadora entre o sujeito que a produz e aquele a quem se destina, logo, neste texto a imagem é considerada como um artefato cultural. Como artefato cultural, ainda que não seja o real, apresenta, representa ou reapresenta o mundo, tornando presente aquilo ou alguém que está ausente. A imagem, especialmente a fotografia, tem o poder de trazer de volta o ausente, o distante, de materializar aos olhos o que não está materialmente ao alcance das mãos.

No presente artigo, busca-se discutir e ampliar o entendimento da análise de imagens no campo da sociologia a partir do aporte oferecido pelo método documentário que tem suas origens na Sociologia do Conhecimento de Karl Mannheim (cf. Weller, 2005; Bohnsack e Weller, 2010). 
Essa disposição exigiu a aproximação de referenciais bibliográficos que, ainda que sumariamente apresentados e reconhecidamente insuficientes analisados, tracem um panorama sobre elementos relacionados e/ou originados na problemática teórico-conceitual da imagem, e que são componentes indispensáveis para sua utilização como fontes documentais.

Como o campo da imagem é vasto e de diferentes composições e tipos, desde as paradas ou em movimento, abrangendo desde a pintura, o cinema, a charge, o vídeo e a TV, até as pichações, tatuagens e as contemporâneas imagens virtuais, porém, este texto volta-se para a fotografia, demonstrando-a como artefato cultural e como documento visual que pode favorecer a investigação da realidade social. Por fim, como exercício analítico, apresenta a utilização do método documentário de interpretação em uma fotografia.

\section{Imagens: artefatos culturais}

O interesse pelos estudos da imagem envolve diferentes enfoques e tradições disciplinares. Segundo Knauss (2006), houve desde a década de 1950 uma reviravolta no lugar da imagem para compreensão da cultura, afirmando que ela se inscreve na área dos estudos culturais, mais especificamente no campo da cultura visual. Conforme o autor, o termo pictorial turn é inspirado em Richard Rorty e no termo linguistic turn - virada linguística - que promove uma ressignificação da linguagem. O pictorial turn - virada pictórica - enfatiza o figurado como representação visual, destacando os modos de ver e a experiência visual dos spectatorship - sujeitos/espectadores -, o que exige um redimensionamento dos estudos da imagem abrindo o campo para interpretações históricas e culturais. Essa denominação é substituída pela visual turn - virada visual - que acentua o visual e a visualização. O autor revela que é com Margareth Dikovitskaya, 
ao discutir as denominações anteriores e aproximando-se teoricamente dos estudos culturais, que o termo cultural turn - virada cultural - é cunhado afirmando-o como mais adequado para o estudo da imagem, posto que considera a imagem como artefato cultural. A partir desta última conceituação, pode-se dizer que

O foco da cultura visual dirige-se para a análise da imagem como representação visual, resultado de processos de produção de sentido em contextos culturais. (...) defendem que os sentidos não estão investidos em objetos. Ao contrário, o conceito de cultura visual sustenta o pressuposto de que os significados estão investidos nas relações humanas (Knauss, 206, p. 114).

De acordo com Meneses (2003), a Cultura Visual engloba diferentes conceitos, recursos e objetivos, porém afirma que há duas vertentes neste campo: a que se refere à comunicação e construção de valores e identidades culturais por mediação visual, a inclusão do visual no processo social, e a que se refere à produção e consumo que envolve o visual, incluindo desde a arte e o design, até as impressões visuais no corpo, como a tatuagem. Podemos dizer também que a imagem produz sentidos, sentidos de realidade, pois "não há SE ou TALVEZ na imagem. A imagem É" (Novaes, 2008, p. 460). As imagens, especialmente o filme e a fotografia, são "signos que pretendem completar identidade com a coisa representada, como se não fossem signos. Iludem-nos em sua aparência de naturalidade e transparência, a qual esconde os inúmeros mecanismos de representação de que resultam" (Novaes, 2008, p. 456).

A resistência em considerar a fotografia como fonte ou instrumento de pesquisa na sociologia se deve às formas de produção do conhecimento que sempre privilegiaram a tradição escrita, de modo que "o problema reside justamente na sua resistência em aceitar, analisar e interpretar a informação quando esta não é transmitida segundo um sistema codificado 
de signos em conformidade com os cânones tradicionais da comunicação escrita" (Kossoy, 2001, p.36). Diferentemente da pintura, a originalidade da fotografia decorre de sua objetividade, ela registra o que está à sua frente, e essa condição "Ihe confere um poder de credibilidade que se encontra ausente em qualquer obra pictória" (Novaes, 2008, p.462).

Para Penn (2008), a imagem difere da linguagem por ser polissêmica ou ambígua; entretanto, uma imagem fotográfica, por aproximar-se com a maior fidelidade do que foi fotografado, é um tipo de signo menos arbitrário ou convencional, pois "no signo indéxico, a relação entre significante e significado é uma relação de contiguidade ou causalidade" (2008, p.323), ou de outra forma, a foto de uma flor é uma flor, a foto de um gato é um gato. Não se pode dizer que a foto de um gato é uma flor, pois nossa visão não vê um gato em uma flor. Porém, a foto de um gato ou de uma flor pode carregar inúmeros significados e permitir várias interpretações ou visões, dependendo de quem a olha, de sua história de vida, de seu lugar no mundo.

No entanto, o reconhecimento da fotografia como fonte documental reside "no fato de que se trata de uma atividade que não foi hierarquizada por nenhum cânone cultural, como ocorreu com a imagem artística" (Meneses, 2003, p.21). Toda fotografia resulta da ação de um homem, aquele que fotografa um sujeito histórico, que, em determinado tempo e lugar, escolheu um assunto e dispôs de certos recursos tecnológicos para realizar o registro de um fragmento do real, ou seja, a fotografia é uma expressão visual, plástica, um artefato que indica a inserção cultural do sujeito que a produz, o contexto representado e os procedimentos técnicos que foram utilizados. Segundo Kossoy (2001), a fotografia carrega em si informações que se constituem a partir de alguns itens interligados e elementares, os quais devem ser considerados quando compuser o corpus de uma pesquisa. O primeiro a ser considerado são os elementos constitutivos da foto, ou seja, o assunto (tema escolhido), o fotógrafo (o sujeito que realiza a foto) e 
a tecnologia (equipamentos e técnicas disponíveis/utilizadas no registro); o segundo são as coordenadas de situação, como o espaço (delimitação geográfica de onde foi realizada a foto) e o tempo (momento histórico da foto), e, o último, o próprio produto final, a foto (a imagem).

Além disso, devemos lembrar o uso de imagens com caráter ideológico e pragmático, fartamente presentes na religião ou na atuação de grupos políticos, ou através da manipulação de imagens que inserem ou apagam registros que atentem contra determinada concepção ou poder instituído. Loizos (2008) destaca duas falácias implícitas na consideração ingênua e objetivista de imagens visuais - delimitados aqui na fotografia como documentos de investigação. A primeira delas se refere a considerar que uma fotografia não mente, revela aquilo que foi registrado. A segunda se refere à afirmação de que a fotografia é universalmente acessível e opera transculturalmente. Quanto à primeira, o autor recorda que impressões fotográficas podem ser alteradas por aerógrafos para retirada ou acréscimo de detalhes ${ }^{1}$, ou superposição de negativos (que colocavam lado a lado pessoas que nunca haviam se encontrado), ao que acrescento o uso atualmente do photoshop amplamente utilizado para corrigir imperfeições nos sujeitos fotografados. Sobre a segunda falácia, demonstra que convenções visuais válidas em um contexto podem ser totalmente desconhecidas em outros, e ainda que existem variações perceptivas e de sentido entre indivíduos, que alteram significativamente a leitura da imagem.

Para Aumont (1993), imagens são objetos construídos por um olhar humano a partir de dispositivos, como a pintura, o cinema e a fotografia. A imagem, segundo o autor, existe para ser vista, logo ela só toma sentido a partir do outro que a vê. Nessa mesma direção, pode-se afirmar que:

1 Um exemplo conhecido de manipulação de imagens é uma foto feita em 30 de abril de 1945 que mostra soldados soviéticos içando a bandeira da União Soviética no alto de um edifício em Berlim. Na foto original, um soldado tem em seu pulso dois relógios, o que indica saque ou roubo. Na foto manipulada, o soldado aparece sem um dos relógios, e há mais fumaça. 
As imagens não têm sentido em si, imanentes. Elas contam apenas — já que não passam de artefatos, coisas materiais ou empíricas - com atributos físico-químicos intrínsecos. É a interação social que produz sentidos, mobilizando diferencialmente (no tempo, no espaço, nos lugares e circunstâncias sociais, nos agentes que intervêm) determinados atributos para dar existência social (sensorial) a sentidos e valores e fazê-los atuar. Daí não se poder limitar a tarefa à procura do sentido essencial de uma imagem ou de seus sentidos originais, subordinados às motivações subjetivas do autor, e assim por diante. É necessário tomar a imagem como um enunciado, que só se apreende na fala, em situação. Daí também a importância de retraçar a biografia, a carreira, a trajetória das imagens (Meneses, 2003, p.28).

Podemos dizer, então, que na imagem há dois sentidos subjacentes: o primeiro material, objetivo, dado pela sua existência, e o segundo subjetivo, da ordem do sujeito que a observa ou que a toma como prova, como fonte, pois

O ato de ler uma imagem é um processo interpretativo resultante da interação entre leitor/a e material. Assim, temos de entender que o sentido dado à imagem irá variar de acordo com os conhecimentos culturais de quem a interpreta, podendo ser bastante universal dentro de uma cultura dada, mas idiossincrática em outra (Herandez e Scarpaaro, 2008, p.62).

Talvez esse segundo sentido tenha sido a causa primeira da desvalorização da imagem como fonte de pesquisas no campo das ciências humanas, desprezá-las pode levar o pesquisador "a deixar de lado não apenas um registro abundante, e mais antigo do que a escrita, como pode significar também não reconhecer as várias dimensões da experiência social e a multiplicidade dos grupos sociais e seus modos de vida" (Knauss, 2006, p.100). 
Do uso da perspectiva à análise de imagens

$\mathrm{Na}$ aproximação da imagem como um artefato e consequentemente, do domínio da técnica, veremos a importância da perspectiva como um elemento que revoluciona a métrica da constituição de imagens. Em qualquer manual de desenho, perspectiva é definida como a fabricação de uma ilusão visual de volume, profundidade e distância dos objetos, e é formada pelo ponto de fuga (direção em que o objeto se aprofunda) e a linha do horizonte (linha que separa o lado superior e o inferior de um objeto). A linha do horizonte é o local onde se localiza o ponto de fuga. Santos e Guedes (2007) destacam que os gregos tinham familiaridade com as leis da perspectiva, pois as grandes tragédias apresentadas teatralmente exigiam a composição de cenários que dessem a ilusão de realidade à cena. Segundo as autoras, Zeuxis e Apollodorus eram os grandes expoentes da pintura grega, que utilizavam os conhecimentos dos geômetras sobre perspectiva e sombra para criar efeitos naturais e ilusões visuais. Eram tão habilidosos que se sabe que o primeiro pintou um cacho de uva tão perfeitamente que os pássaros tentavam bicá-lo. O segundo, rival do primeiro, pintou o cenário de uma paisagem atrás de uma cortina, e para provar que era tão bom ou melhor que Zeuxis, pediu a ele que abrisse as cortinas para que pudesse ver melhor seu desenho, só que esta era parte da pintura.

De acordo com Sampaio-Ralha (2006), a perspectiva se desenvolve no Renascimento modificando a tradição da Idade Média de representar o mundo espiritual e não o natural. E foi com Leon Battista Alberti, em 1435, em De Pictura, que foram realizadas as primeiras formulações das leis da perspectiva. Com Piero Della Francesca, em De Prospectiva Pingendi, a perspectiva tornar-se-ia o método das artes plásticas. Filippo Brunelleschi acrescenta à representação do espaço renascentista a geometria ao projetar a abóboda da Catedral Santa Maria Del Fiore, antes de 
construí-la. Esta visão que só vai ser contestada pelo Cubismo e radicalizada polemicamente por Picasso e Kandinsky.

A perspectiva foi considerada por muito tempo como a forma realista e objetiva de representar o espaço tridimensional, e a forma ideal para a representação gráfica do espaço (Fragoso, 2004). De acordo com Aumont (1993), perspectiva deriva do latim perspicere, que significa "ver claramente", "ver através de" e é um método de representação de objetos tridimensionais em uma superfície plana, com o papel de reconstituição mental de volumes projetados e sua disposição no espaço. Segundo o autor, há a perspectiva linear (designada inicialmente de perspectiva naturalis), a qual é a projeção a partir de um ponto de fuga localizada em uma linha de horizonte qualquer, onde o que está mais distante tem tamanho menor e maior à medida que se torna mais próximo do campo de visão, já que as retas convergem para um ponto ou o ponto de fuga. Há também a perspectiva artificialis ou geométrica, que desenvolveu a solução ao problema de acrescentar profundidade e volume às imagens, sendo largamente utilizada na pintura e na fotografia. Como formadora do olhar, a perspectiva era um elemento fundamental para a compreensão da obra, e poder-se-ia supor que, desnaturalizada pelas deformações ou ausências cunhadas pelos movimentos artísticos que contestavam o natural e a reprodução do real, ela teria sido abandonada. Porém, tanto o cinema, a televisão, quanto a fotografia continuam utilizando seus princípios, uma vez que representa a tridimensionalidade em superfícies planas (Fragoso, 2004).

Porém, apesar da técnica da perspectiva ser conhecida desde a antiguidade, a análise de imagens, de acordo com Meneses (2003), só se consolida no século 18 com a constituição do campo da História da Arte. No Renascimento, antiquários dos séculos 16 e 17 coletaram e organizaram imagens e decodificaram significados simbólicos de moedas, esculturas, pinturas de catacumbas, entre outros, e essa prática conduziu mais 
tarde à iconografia. Contudo, é somente entre fins do século 19 e início do século 20 que a História da Arte reconhece o status da imagem como fonte icnográfica, especialmente no campo da História Cultural, buscando significados antropológicos, geográficos e históricos, e como marca documental e classificatória (cf. Meneses, 2003, p.13).

A Antropologia, depois da História da Arte, é a ciência que passou a se ocupar com os registros visuais, destacando especialmente a fotografia. Ainda que inicialmente vinculados à antropometria e à premissa positivista de neutralidade da observação, esses estudos contribuíram, desde a década de 1960, para que a visualidade fosse associada às discussões sobre a cultura. Já não era suficiente observar as manifestações simbólicas, artísticas e culturais dos grupos sociais, ou seja, observar o visível para então inferir o não visível: era necessário passar do visível para o visual, para uma Antropologia do Olhar. A antropologia do olhar, atualmente denominada de Antropologia Visual, se organiza a partir do "reconhecimento do potencial informativo das fontes visuais, foi capaz de tomar consciência da sua natureza discursiva" (Meneses, 2003, p.16). A partir dessa transformação, as fontes visuais, consideradas documentos, passaram a ser analisadas quanto ao registro produzido pelo observador, quanto ao registro ou parte do observável, na sociedade observada, e quanto à interação entre observador e observado. Tomar a imagem como documento resulta, portanto, do esforço de diferentes áreas das ciências humanas em valorizar a dimensão visual da vida social (cf. op. Cit.).

\section{O método documentário e a interpretação da imagem}

Assim como em outras disciplinas, a sociologia recusou a imagem visual como fonte documental nos seus primórdios. Segundo Martinez (2006), uma das razões dessa exclusão se deve ao fato da sociologia 
delimitar-se como campo científico, afastando-se de tudo que pudesse questionar a exatidão de suas interpretações. No campo da empiria, optou principalmente por procedimentos de análise pautados nos métodos quantitativos e estatísticos, de tal modo que

Essa exclusão de materiais visuais na sociologia fez com que os métodos utilizados por sociólogos não se tornassem adequados para a análise e utilização de imagens. O sociólogo que hoje em dia se propõe a utilizar imagens em suas pesquisas se verá diante do problema de ter que estabelecer um método apropriado para a análise e para o uso deste material visual (Martinez, 2006, p. 392 - trad. nossa).

Recentemente e talvez motivada pela inquestionável importância social que a imagem visual assumiu desde o século 20, a sociologia começa a reconhecer a imagem visual como documento. Aceitar que imagens têm status de documento exige um esforço de elaboração de procedimentos metodológicos que permitam sua compreensão. Nesse sentido, Karl Mannheim (1964 e 1980) desponta como um teórico que contribui para essa tarefa a partir do desenvolvimento do método documentário de interpretação (cf. Bohnsack, 2007, 2007a, 2009 e 2010). Mannheim desenvolveu um método para a compreensão da Weltanschauung - visões de mundo - de um determinado grupo social, considerando tanto os produtos culturais privilegiados como a arte, quanto as ações cotidianas, como objetos passíveis de análise sociológica (cf. Weller et al., 2002). Ao voltar seu olhar para o estudo dos fenômenos sociais, especificamente para a Weltanschauung, o autor reconhece os limites imputados pela tradição da ciência social positivista, chamando ainda a atenção para o fato de que "todo produto ou manifestação cultural deva ser considerado em uma totalidade, cujas experiências diárias, imediatas, não são partes de um todo claro/racional, mas constitutivos do real/racional" (op. cit., p. 381). 
Elaborado na década de 1920 do século passado, o método proposto por Mannheim foi reconhecido e adaptado no campo da História da Arte por seu contemporâneo Erwin Panofsky, historiador da arte, que, ao desenvolver uma teorização sobre a imagem, um modelo iconográfico/ iconológico como método de análise científica da arte, recorreu à diferenciação mannheimiana entre sentido imanente e sentido documentário para aprofundar a distinção entre o nível pré-iconográfico e iconográfico (cf. Bohnsack, 2009 e 2010). A aproximação entre os dois campos, História da Arte e Sociologia, potencializou o desenvolvimento, tanto em um quanto no outro, da ressignificação de procedimentos teórico-metodológicos para a análise de imagens ${ }^{2}$. A proposta de Karl Mannheim, conforme Martinez (2006), "não só oferece uma técnica de análise da imagem, mas, por sua vez, constitui um método que está predestinado a fazer uso da imagem, desta vez, não como objeto de estudo mas como técnica de análise sociológica" (p. 393 - trad. nossa).

O método documentário tem por objetivo a análise de visões de mundo que resultam de "uma série de vivências ou de experiências ligadas a uma mesma estrutura, que por sua vez constitui-se como base comum das experiências que perpassam a vida de múltiplos indivíduos" (Mannheim, 1980, p. 101 - trad. nossa). Interconectadas, essas experiências ou vivências podem derivar na formação de grupos sociais e suas concepções, ou de outro modo, o método proposto por Mannheim constitui-se em um procedimento de análise de fenômenos culturais, especialmente aqueles desvalorizados pelas ciências sociais de influência positivista. De acordo com essa compreensão, toda experiência merece ser interpretada e cada elemento da observação integra e constitui uma totalidade cultural, logo os objetos culturais são veículos de sentido e se

2 Para mais detalhes sobre as aproximações entre a Iconologia de Panofsky e o método documentário de Mannheim, ver Michel (2001 e 2007). 
propõem a realizar uma compreensão profunda dos significados, visões de mundo (cf. Mannheim, 1964 e 1980).

O procedimento de investigação desenvolvido por Mannheim não tem como destino somente obras consagradas ou de cunho artístico, pois ele concebe que toda produção cultural de uma dada sociedade é passível de investigação. Ou seja, "se poderia afirmar que o método de interpretação documentária consiste em ampliar o campo de estudo, do campo da arte a toda cultura visual" (Martinez, 2006, p. 402 - trad. nossa). O teórico identifica três níveis de sentido a serem considerados na análise de todo objeto cultural: o imanente, o expressivo e o documentário. O sentido objetivo ou imanente é dado ao pesquisador naturalmente, pois se refere à configuração social objetiva, a qual é intrínseca ao tema do tema/ grupo/conjunto de experiências investigado, e neste momento não carece de outras informações, pois utilizará o conjunto de suas experiências culturais para apreendê-lo, e/ou identificar estilos de representação nas imagens. O sentido expressivo exige a análise do motivo ou as intenções subjacentes ao que o artista, neste texto o fotógrafo, pretendeu demonstrar. O sentido documentário está relacionado às reconstruções que são feitas a partir da fonte/experiência analisada naquilo que manifesta como concepção de mundo (cf. Weller et al., 2002).

Com base na diferenciação dos três níveis de sentido apresentados por Mannheim, o sociólogo Ralf Bohnsack atualizou interpretação documentária, tanto do ponto de vista do método como da metodologia, e a transformou em um instrumento de análise para a pesquisa social empírica de caráter reconstrutivo a partir dos anos 1980. Nessa revisão, o nível documentário é reposicionado para o centro da análise empírica, e a aplicação do método é operacionalizada em duas etapas: interpretação formulada e interpretação refletida (cf. Weller, 2005). Durante a interpretação formulada, o pesquisador realiza a análise detalhada do 
sentido imanente e a decodificação do seu sentido coloquial, descrevendo o conteúdo sem fazer comentários ou interpretações. A interpretação refletida se refere ao momento em que as interpretações são elaboradas a partir do exame minucioso do conteúdo dos sujeitos/experiências/objetos culturais analisados. Analisar a imagem como documento no método documentário significa passar do nível imanente/literal/icnográfico para o sentido documentário/iconológico, o que exige uma mudança também no procedimento de análise, que mudança remonta à abertura do questionamento sobre o quê (was) para o questionamento sobre o como (wie), da questão o que são fenômenos culturais e sociais para a questão como eles são produzidos (cf. Bohnsack e Weller, 2010; Bohnsack, 2010a).

\subsection{A fotografia: registros de visões de mundo}

Entre todas as possibilidades de materialização das imagens visuais, optamos neste texto pela imagem visual fotográfica, concebendo a fotografia como artefato cultural, produto das relações sociais, e pela sua consequente singularidade como reveladora da Weltanschauung. Costumamos dizer que a fotografia é um recorte de tempo e espaço, é um registro marcado e situado, e no mundo cada vez mais marcado pela virtualidade e transitoriedade, pelo efêmero, fluido, líquido ou liquefeito, como apontado por Baumam (2001). O ato de olhar uma imagem fotográfica é também

a chance de imprimir sobre a imagem certa dose de desejos e questionamentos, construindo vínculos um tanto raros em nossas experiências midiáticas. Trata-se de substituir a velocidade (uma porção de espaço percorrido numa porção de tempo) pela densidade (uma porção de tempo condensada naquela porção de espaço) (Entler, 2007, p. 45).

Se toda foto é um registro de algo ou alguém em determinado tempo e lugar, toda foto traz em si uma trajetória única. Toda foto está marcada por uma intenção de ação, seja ela oriunda do próprio fotógrafo, ou 
demandada por outros, e, após sua materialização, revelada ou impressa, é também marcada pelos sentimentos que provocou, as memórias que fez emergir, os lugares que ocupou. Na foto, o tempo é atemporal, pois tornado foto o instante recortado, marcado, registrado, pode ser visto em outros tempos, com outros olhos e olhares.

A fotografia surge no século 19, no contexto da Revolução Industrial, e teve papel fundamental e inovador para informar e dar conhecimento da realidade social. Com o desenvolvimento da câmera fotográfica e seu resultado material, a fotografia, o mundo tornou-se conhecível para além das fronteiras da tradição escrita, verbal ou pictórica, e com o desenvolvimento da indústria gráfica, potencializou-se o conhecimento do mundo a partir de fragmentos do olhar, do contexto. Fragmentos do olhar porque "toda fotografia tem sua origem a partir do desejo de um indivíduo que se viu motivado a congelar em imagens um aspecto dado do real, em determinado lugar e época" (Kossoy, 2001, p.36).

O entendimento dos fundamentos da representação tridimensional do espaço por câmeras é conhecido há milhares de anos. Desde Mo Ti, filósofo chinês que no século 5 A.C. descreveu a formação de uma imagem externa em uma parede de um quarto escuro, a partir da entrada da luz por uma pequena abertura, até nas reflexões e nos estudos de Aristóteles e Leonardo da Vinci. Entretanto, só no século 17, Kepler cria o conceito de câmera escura, para designar um ambiente, sala ou tenda, ou caixa, com uma abertura com lente. Seu princípio ótico fundamental é que os raios de luz projetam-se em linha reta. Esse fundamento foi largamente utilizado por pintores, como ferramenta que auxiliava o desenho (Fragoso, 2004). A câmera fotográfica, seja através de técnicas de fixação fotoquímica (sistema analógico) ou de codificação binária dos padrões de luz (sistema digital), mas nos dois casos através de um mecanismo óptico que vincula a luz entre uma superfície de registro e os elementos escolhidos 
de uma determinada cena (Fragoso, 2004), materializa extratos da realidade, garantindo uma existência atemporal à sua provisoriedade.

A fotografia de arquivos pessoais é um instrumento de mediação entre o fotografado e sua imagem, na medida em que o sujeito fotografado interfere na execução da foto, demonstrando necessidade de controlar sua própria imagem ou a de outrem, como as de seus filhos, sua casa, sua vida. O fotografado se arruma e arruma, delineia o que deve ser recortado e congelado, autoriza o que pode e deve ser colocado à vista de si e, assim, neste jogo de estabelecimento de sentidos, a fotografia assume "o papel de mediação das imagens nos processos sociais" (Novaes, 2008, p. 462). As escolhas do assunto, e da organização visual, documentam a compreensão do fotógrafo diante do tema registrado, pois qualquer que seja o assunto registrado na fotografia, esta também documentará a visão de mundo do fotógrafo. A fotografia é, pois, um duplo testemunho: por aquilo que ela nos mostra da cena passada, irreversível, ali congelada fragmentariamente, e por aquilo que nos informa acerca de seu autor (Kossoy, 2001, p.50).

A fotografia também se faz presente em estudos e relatórios investigativos sobre as relações de gênero, história do cotidiano, das crianças, mas, em muitos casos, adquire apenas o papel de ilustrar o texto. Embora sejam fartamente utilizadas, "não têm relação documental com o texto, no qual nada de essencial deriva da análise dessas fontes visuais; ao contrário, muitas vezes algumas delas poderiam mesmo contestar o que vem dito e escrito" (Meneses, 2003, p.21). O papel do investigador social, do sociólogo que utiliza a imagem como documento, segundo Martinez (2006), não é o de tratar de questões estéticas nem de significados imediatamente apreendidos pelo olhar, mas seu interesse deve ser sobre a informação social que está presente nas imagens, ou seja, a característica da posição social do artista em sua época e o momento histórico e social em que foi realizada a produção da imagem. 
Bohnsack (2007, 2007a e 2009) afirma que, no campo da fotografia, é necessário diferenciar duas categorias de produtores de imagem: os produtores de imagem que representam e os produtores de imagem representados. Os primeiros seriam aqueles que estão na produção da imagem, seja antes, durante ou depois do seu registro, o fotógrafo ou o artista. A segunda categoria se refere àqueles que estão diante da câmera, sejam pessoas, criaturas ou cenas sociais. Em sua opinião, o dilema metodológico que poderia surgir da diferença entre essas duas categorias se resolve quando ambos, os que representam e os representados, pertencem ao mesmo Erfahrungsraum - espaço de experiências - de acordo com o conceito mannheimiano. Do contrário, acessar a interpretação que documente ou reconstrua trajetórias coletivas de vida se torna muito mais complexo, pois não há congruência contextual, cultural entre eles.

Essa dificuldade está demonstrada na análise realizada por Bohnsack de uma fotografia de Sebastião Salgado, intitulada Família com onze filhos no sertão do Tauá, Ceará, 1983, na qual ele indica que, como produtor de imagem que representa, Sebastião Salgado, na coreografia cênica da imagem, promove uma associação entre pobreza e número de filhos, um estigma marcadamente presente na percepção objetivista de famílias pobres. Segundo o autor, a foto também expressa interesses diferentes entre as duas categorias, os que representam e os representados, pois enquanto um está preocupado com revelar a condição humana, o/s outro/s parecem ter atitudes de resistência, vergonha ou indiferença (cf. Bohnsack, 2007, p. 249-257): 


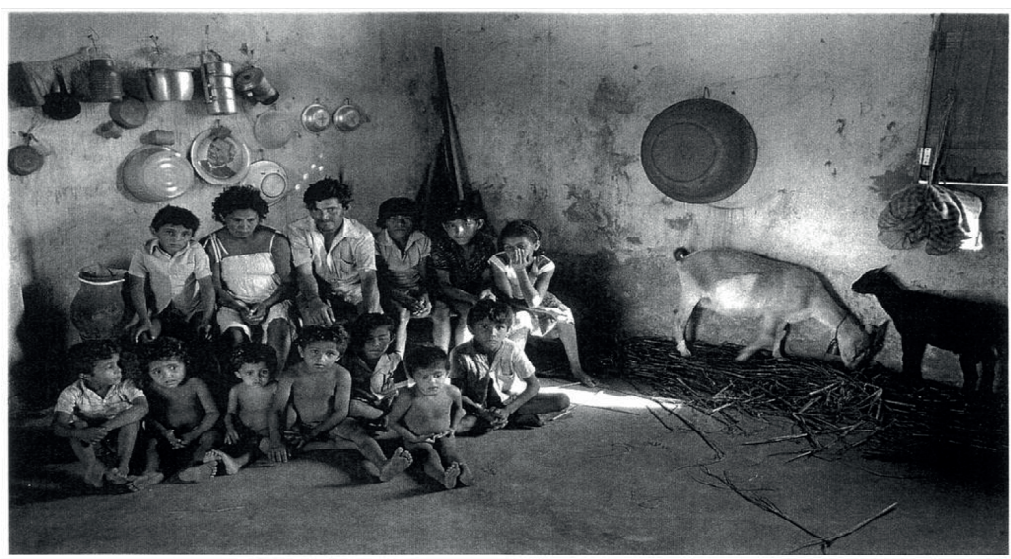

In: Sebastião Salgado,1997 reproduzido em Bohnsack, 2007, p. 249.

Embora fotógrafo e família pertençam ao mesmo país, sejam brasileiros, há diferenças de experiências de vida entre eles que "aparecem" no registro. Sebastião Salgado é considerado um dos fotógrafos representantes do fotojornalismo engajado, e ancora a produção de suas imagens na matriz marxista, construindo uma narrativa de imagens com caráter de crítica e denúncia (Mauad, 2008). Para os produtores de imagem representados, os membros da família, o ato de ser fotografado representa o registro de si, impresso e colocado à vista do outro. Mas, certamente, não compreenderam esse mesmo ato como uma ação de engajamento social, e utilização de uma formação profissional, como estratégia de denúncia da exploração da sociedade capitalista. Esse descompasso é identificado pelo pesquisador como uma clara discrepância entre o meio social em que cada um, fotógrafo e família, está inserido.

2.2 O processo de interpretação da imagem fotográfica

Associando instrumentos metodológicos da História da Arte de Erwin Panofsky, e da Sociologia do Conhecimento de Karl Mannheim, 
Bohnsack (2007, 2009 e 2010) descreve as etapas da análise de imagens segundo o método documentário de interpretação. Para alcançar o nível documentário na análise de imagens, o pesquisador deve "colocar entre parêntesis todo e qualquer conhecimento biográfico sobre a família" (Bohnsack, 2007a, p. 299), colocando de lado os nomes próprios ou sobrenomes que deem indício biográfico do fotografado.

Partindo da conexão com a Teoria da Iconologia de Panofsky, Bohnsack afirma que a interpretação de uma fotografia deve iniciar-se no nível pré-iconográfico, a qual se refere à estrutura formal da imagem. A estrutura formal da imagem comporta três dimensões: a estrutura planimétrica total, a coreografia cênica e a projeção perspectivista. Só assim será possível apreender a imagem como um sistema auto-referente, de forma que pela estrutura formal é possível traçar um caminho que leva à compreensão da especificidade do espaço de experiências conjuntivas dos produtores de imagens (cf. Bohnsack, 2010). O autor associa as três dimensões da Teoria da Iconologia às duas etapas desenvolvidas pelo Método Documentário, para a análise de imagens da seguinte maneira: a) A interpretação formulada compreende a análise do nível pré-iconográfico (os planos da imagem) e a análise dos elementos iconográficos (tipificações do senso comum); b) A interpretação refletida está composta da análise da composição formal, subdividida em análise da composição planimétrica, análise da projeção perspectivista, análise da coreografia cênica e interpretação icônico-iconológica.

\subsection{Análise de uma fotografia de família segundo o método documentário}

A escolha da fotografia que será analisada a seguir pode ser vista como um contraste máximo aos produtores de imagem representados por Sebastião Salgado, ainda que ambas as famílias sejam oriundas da mesma região ${ }^{3}$ :

3 Foto gentilmente cedida pelo Profo Dr. Gouvan de Magalhães, de seu arquivo pessoal. 


\section{IMAGEM 1}

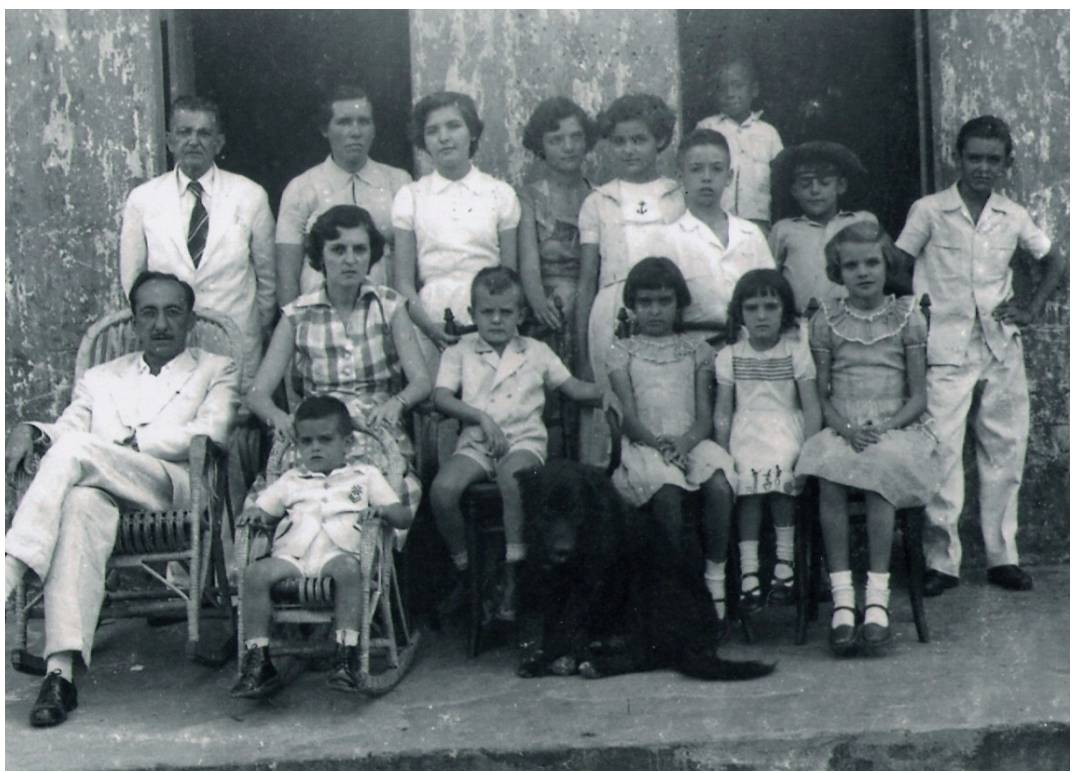

Foto original: Família de proprietários de terra em Pedra Branca - Ceará/Brasil, 1951

\section{A interpretação formulada}

No que se refere à primeira etapa do método, podemos dizer que se trata de uma foto de família do interior do nordeste brasileiro, e numerosa. A foto da família Cavalcanti é composta por nove crianças, três adolescentes, quatro adultos e um cachorro. O grupo de crianças e adolescentes é constituído por seis meninas e seis meninos. Entre os adultos, dois são muIheres e dois são homens. No primeiro plano, há uma separação geracional. Os adultos e as crianças mais velhos estão em pé atrás, e os adultos e as crianças mais novas estão na frente. Na imagem vemos três gerações, atrás estão posicionados os adultos, os adolescentes e as crianças mais velhos e 
na frente estão os adultos mais jovens e as crianças. No plano intermediário, vemos a parede de uma casa, descascada, com uma porta à esquerda e uma janela à direita. Ao fundo, vemos um menino posicionado atrás da janela e do grupo de crianças, logo, do lado de dentro da casa e, em cima de algo que o faz mais alto que todos os que estão à sua frente.

Com relação à análise dos elementos iconográficos, pode-se ver claramente que houve uma preparação tanto por parte do produtor da imagem que representa, o fotógrafo, quanto do produtor da imagem representada, a família, que se reflete ao figurino utilizado para a composição da imagem. Os homens adultos estão de terno, os meninos maiores vestem calça comprida e camisas, os meninos menores trajam calças curtas e camisas com abotoamento duplo ou com bordado. Porém, um dos meninos usa chapéu. As mulheres adultas usam vestidos com detaIhes como bordado, gola, manga, assim como os vestidos usados pelas meninas, sendo que apenas uma das meninas está com um vestido com decote. As meninas menores usam vestidos adornados e abaixo dos joelhos. Todas as meninas e meninos, e o adulto mais jovem que estão na primeira fileira estão com sapatos e meia. Todas as pessoas da foto estão com os cabelos cuidadosamente penteados, e todas as mulheres, adultas ou não, usam cabelos curtos e modelados. Há uma exceção na foto. O menino que está do lado de dentro da casa é a única criança que veste uma camisa simples, sem bordados, gola, detalhes ou duplo abotoamento. Sua camisa está desalinhada e desabotoada a partir do segundo botão.

A interpretação refletida

O segundo momento da interpretação inicia com a análise da composição formal da imagem, tendo como ponto de partida a análise da composição planimétrica, a qual é, de acordo com Bohnsack (2009 e 2010), delineada a partir da identificação de linhas horizontais e verticais que compõem a imagem. 
IMAGEM 2

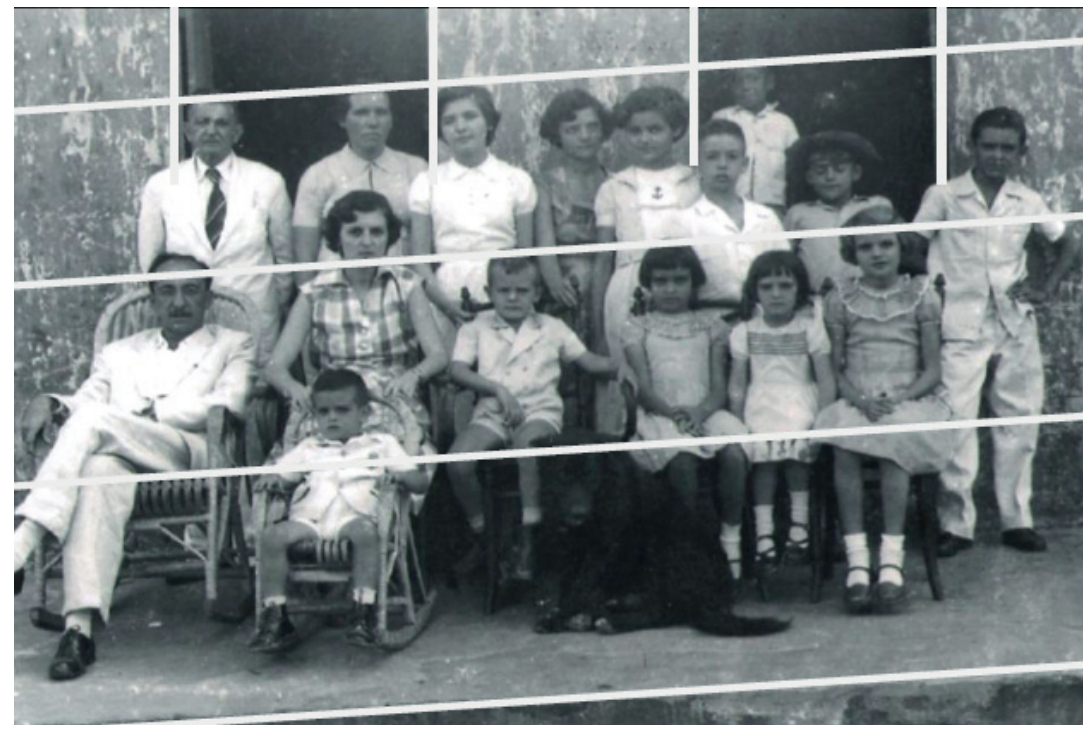

A composição da imagem está marcada pela escolha da frente da casa como um lugar de referência da família, e por quatro linhas horizontalmente inclinadas, em um ângulo de $15^{\circ}$, que acompanham a métrica da construção e do terreno, ambos inclinados. A primeira linha passa rente aos pés do adulto mais novo, do menino sentado na cadeira, das patas do cachorro e dos pés de uma das meninas sentadas. A segunda linha passa rente à cabeça do cachorro. A primeira e a segunda linha delimitam integralmente o cachorro como o único personagem que está situado na parte inferior da foto, embora ocupe o centro dela. A terceira linha passa acima da cabeça do homem mais novo, de dois meninos e três meninas, todos sentados. A quarta linha passa acima da cabeça dos adultos, meninos e meninas mais velhos. A terceira e a quarta linha separam todos os mais velhos, apesar de incluir o rosto da mulher mais jovem. 
Além destas, há quatro linhas verticais que delimitam o plano intermediário e o fundo, e delimitam dois casais: um casal formado pelos adultos mais velhos, e um casal formado pelos adultos mais jovens. Essas linhas também separam do grupo fotografado um dos meninos, que está do lado de dentro da casa, com figurino diferente dos outros fotografados, e que é negro. O ângulo das linhas horizontais projeta-se em direção aos adolescentes e às crianças, dando uma ideia de ampliação e longevidade, continuidade da família, enquanto que as linhas verticais separam do grupo de fotografados um dos meninos, o que está atrás da janela. A composição total da fotografia mostra a família no centro da imagem, ocupando todo o espaço da foto. É retratada em um ambiente familiar - a frente da casa -, embora impessoal na composição da foto - não se mostra a casa, apenas portas e janelas -, o que coloca a família como o tema da foto e ocupando centralidade na imagem.

O segundo momento da análise da composição formal se refere à composição perspectivista, ou seja, em como a imagem impressa pode ser vista, a partir da aplicação dos aspectos relacionados aos princípios da perspectiva e relativos ao olhar que o produtor da imagem que representa, o fotógrafo, imprime como seu na imagem, e ao mesmo tempo como os produtores da imagem que representam, a família, permitem-se ver. A perspectiva, nesse sentido, assume um lugar destacado na análise da imagem, pois possibilita "o desenvolvimento de uma perspectiva sobre os produtores da imagem e suas visões de mundo" (Bohnsack, 2007, p. 303). 


\section{IMAGEM 3}

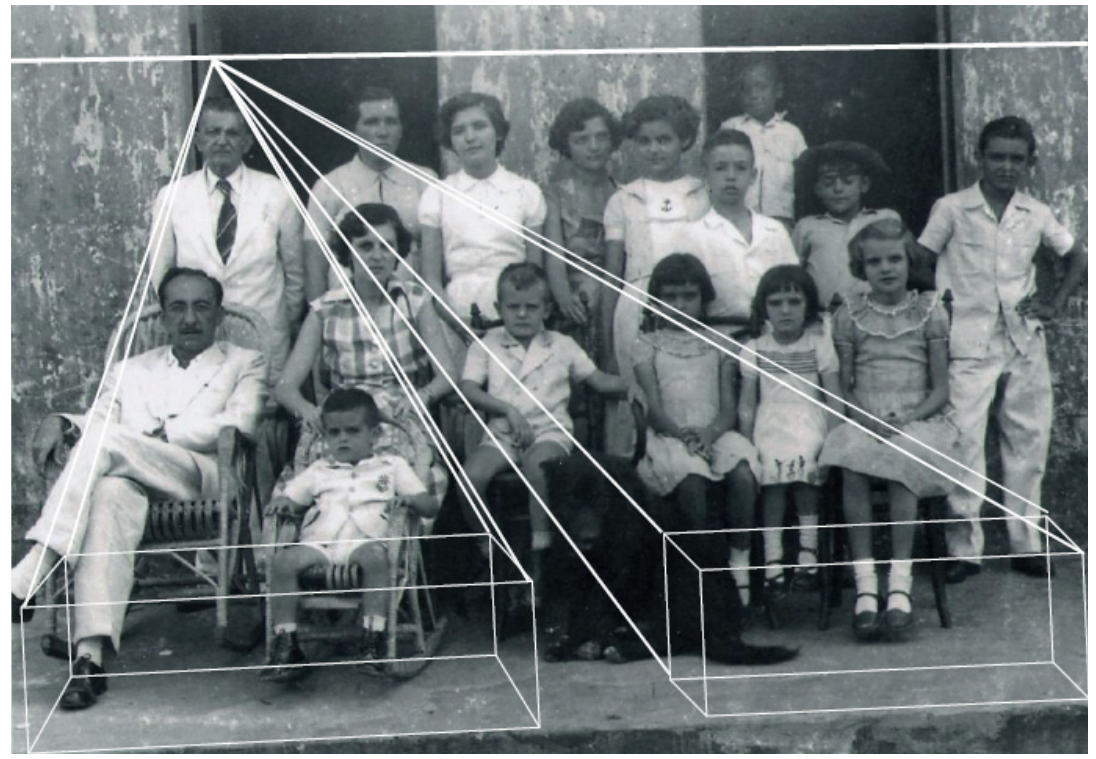

É importante lembrar que em fotografia a posição do fotógrafo pode ser identificada pelos padrões de luz e sombra, pelo olhar do fotografado, e pela localização do foco da imagem. Assim, a partir da aplicação dos princípios da perspectiva, notamos que as crianças estão desfocadas, e entre todas elas, o mais desfocado é o menino atrás da janela. Logo, o centro perspectivista não está centrado em todo o grupo, mas nos homens, especialmente no homem mais velho, o patriarca da família. A linha horizontal na qual se encontra o ponto de fuga passa por cima da cabeça do homem mais velho, de modo que não alcança os meninos e as meninas, nem as mulheres adultas. Com base nisso, podemos afirmar que, na forma de organização espacial e padrão de visibilidade do grupo, o caráter geracional e de gênero marca a imagem da família Cavalcanti. 
Os homens adultos estão separados das mulheres, dos adolescentes e das crianças, com exceção de uma delas, um menino na cadeira de balanço.

A última parte da análise da composição formal está relacionada à coreografia cênica, ou seja, a forma como as pessoas são apresentadas e organizadas para a produção da imagem. Do conjunto de pessoas, 14 estão dispostas em duas fileiras, e duas crianças estão fora delas. Os adultos estão à esquerda da foto, e as crianças e os adolescentes estão em um grupo à direita, exceção feita a uma criança, um menino, que está à esquerda e à frente de todos os adultos. Todos os que estão na frente estão sentados em cadeiras de diferentes tamanhos e formatos. Do grupo de meninas sentadas, duas meninas estão em cadeiras, e a menina do meio, a menor delas, está sentada em um banco, sendo que o menino ao lado delas está numa cadeira maior e com braços, tão grande quanto a que a mulher à sua esquerda está sentada. O homem adulto e o menino à esquerda da foto estão sentados em cadeiras de balanço de tamanhos diferentes.

Porém, dois meninos destoam da formalidade do grupo. O menino à direita está meio encostado na parede, com uma das mãos atrás da costa. O outro, o menino de chapéu, está com os braços apoiados na janela, o que projeta seu corpo para frente. Esses dois meninos parecem encarar o momento da foto como uma diversão, não dando a ele a seriedade e o rigor que os outros demonstram. As duas crianças que aparecem fora das duas fileiras são meninos. Um deles está à frente do grupo de adultos, e próximo à mulher sentada, que está segurando a cadeira com as duas mãos. O outro está atrás da segunda fileira. Há na foto um cachorro grande, bem tratado, que está posicionado na frente das duas fileiras de crianças, sendo apresentado na foto como um animal que faz parte da convivência familiar, especialmente das crianças. No fundo, vemos que o menino que está fora das fileiras é a única pessoa negra da foto.

A etapa final da interpretação refletida constitui o momento da interpretação icônico-iconológica. Podemos afirmar que o poder aquisitivo 
da família é informado pela forma como estão trajados para a foto, e que o modo como as pessoas das fotos estão vestidas indica que a família tem uma condição econômica privilegiada. Um dos meninos, que está de chapéu, está na foto, mas ao mesmo tempo assume o lugar de quem está subvertendo a ordem proposta na visualização do resto do grupo, uma vez que posa descontraído - está com os dois braços apoiados na janela - e desatentamente - olhos fechados - para o fotógrafo.

A foto indica que os fotografados tiveram a intenção de resguardar para outros olhos sua imagem como uma família grande e com uma hierarquia geracional, centrada na figura paterna, e ainda que o animal da foto, um cachorro, é um animal de estimação.

\section{Considerações finais}

Analisar imagens é desafiar séculos de práticas de investigação da sociedade, as quais tentaram quantificá-la ou compreendê-la através dos sujeitos de um determinado contexto. É tomar para si uma tarefa que exige aprofundamento de referenciais teóricos de diferentes áreas. É estar aberto a assumir o risco de envolver-se com fontes tradicionalmente desconsideradas ou desvalorizadas pela pesquisa social. A análise de imagens a partir do método documentário pretende ser uma alternativa para pesquisadores da área social em direção à construção de um olhar revelador de visões de mundo, de enteléquias, no sentido mannheimiano.

Nesse sentido, demonstramos as etapas de análise de fotografias segundo o método documentário, utilizando neste artigo uma foto de família de alto poder aquisitivo, representada em três gerações. Destacase na fotografia a presença da geração mais jovem, meninos e meninas, indicadores do crescimento da família, de sua continuidade e ampliação, bem como de sua posição de classe. Ao contrário de outras imagens de 
família nas quais o número de filhos é associado à pobreza, a foto revela a importância da descendência como indicador de bem-estar e sucesso familiar. O numeroso grupo de pessoas mais jovens que compõem a foto demonstra o valor atribuído à continuidade e à ampliação do número de pessoas na família. Além disso, há uma demarcação clara na estrutura de gênero, centrada na figura do patriarca. Podemos dizer que a família retratada, enquanto produtores de imagem representados, e o fotógrafo, enquanto produtor de imagem que representa, partilham da mesma compreensão do momento de ser fotografado e fotografar.

Assim, uma foto como esta, de arquivo particular, perdida entre centenas de outras que guardam lembranças aos seus descendentes, carrega muito mais que sentimentos de uma linha familiar, pois são fontes incomensuráveis de visões de mundo, de registro de formas de apreensão de sentidos e significados sobre modos de ser e estar, de pertencer a uma determinada época, classe e estrutura de gênero na família.

\section{Images: documents of worldviews}

\section{Abstract}

We live in a hyper-visual world, where the image plays a key role in identification, ideological unveiling and socialization of meanings. But for a long time the image was neglected in the context of qualitative research methods. In this sense, it is essential that the human and social sciences recognize the potential of images for the purposes of social investigation, even though creating them might be characterized as an activity that requires expertise. Image analysis is not a simple task, easily accessible to any researcher, since overcoming the inherent level of interpretation, or the level of common sense, requires deepening the theoretical frameworks that help to read beyond what it tells at a first look. In this sense, this paper presents a practical exercise of a photograph analysis based on the documentary method, which has its origin in Karl Mannheim's Sociology of Knowledge. The adaptation of the documentary method for image analysis was developed by 
Ralf Bohnsack, who, to that end, also returned to the theory of Iconography by Ervin Panofsky and the contributions of authors such as Max Imdahl and Roland Barthes. With this article we aim to offer a counterpoint to the recurring criticism that claims lack of theoretical grounding, reflection, and methodological rigor in both the treatment and the analysis of data. At the same time, we intended to encourage the inclusion of other sources in addition to text/interview and observation, such as photographs, images and movies, in the qualitative research.

Keywords: Image. Photograph. Image analysis. Documentary method. Qualitative methodologies.

\section{Referências}

BARBOZA MARTINEZ, Amália. Sobre el método de la interpretación documental y el uso de las imágenes en la sociología: Karl Mannheim, Aby Warburg y Pierre Bourdieu. Sociedade e Estado. Brasília, v. 21, n. 2, Agosto de 2006.

BAUMAN, Zygmunt. Modernidade líquida. Rio de Janeiro: Jorge Zahar Editor, 2001

BOHNSACK, Ralf. Rekonstruktive Sozialforschung: Einführung in Qualitativen methoden. 6. ed. Opladen: Barbara Budrich, 2007.

BOHNSACK, Ralf. Qualitative Bild - und Videointerpretation. Opladen \& Farmington Hills: Barbara Budrich, 2009.

. A interpretação de imagens e o método documentário. Sociologias, Porto Alegre, Ano 9, no. 18, jun./dez. p. 286-311, 2007a.

. Zum Verhältnis Von Bild- und Textinterpretation in der qualitativen Sozialforschung. In: FRIEBERTSHÄUSER, Barbara; FELDEN, Heide; SCHÄFFER, Burkhard (Orgs.). Bild und Text. Methoden und Methodologien visueller Sozialforschung in der Erziehungswissenchaft. Opladen: Barbara Budrich, 2007b. p. 21-45.

. Interpretação de imagens e o método documentário. In. WELLER, Wivian; PFAFF, Nicolle (Orgs.). Metodologias da Pesquisa Qualitativa na Educação: Teoria e Prática. Petrópolis: Vozes, 2010. p. 114-134.

BOHNSACK, Ralf; WELLER, Wivian. O método documentário na análise de grupos de discussão. In. WELLER, Wivian; PFAFF, Nicolle (Orgs.). Metodologias da Pesquisa Qualitativa na Educação: teoria e prática. Petrópolis: Vozes, 2010. p. 67-86. 
ENTLER, Ronaldo. A fotografia e as representações do tempo. Revista Galáxia, São Paulo, n. 14, p. 29-46, dezembro de 2007. Disponível em: < http://revistas. pucsp.br/index.php/galaxia/article/viewFile/1485/956 >. Acesso em 14 de novembro de 2009.

FRAGOSO, Suely. Calidoscopia midiática: da criação à ressignificação das imagens em perspectiva. Intexto, Porto Alegre: UFRGS, v. 2, n. 11, p. 1-13, julho/ dezembro, 2004.

HERNANDEZ, Aline; SCARPARO, Helena. Silêncios e Saberes Guardados nas Imagens do Pré-Golpe de 1964. Revista de Psicologia Política, São Paulo, v.8, n. 15, abril de 2009. Disponível em: < http://www.fafich.ufmg.br/ psicopol/seer/ ojs/viewarticle.php?id=139>. Acesso em: 01 de dezembro de 2009.

KNAUSS, Paulo. O desafio de fazer História com imagens: arte e cultura visual. Artcultura, Uberlândia, v. 8, n.12. janeiro/junho de 2006. Disponível em: <http:// www.artcultura.ppghis.inhis.ufu.br/viewarticle.php?id=130>. Acesso em: 15 de novembro de 2009.

KOSSOY, Boris. Fotografia e História. 2a ed. rev. São Paulo: Ateliê Editorial, 2001. LOIZOS, Peter. Vídeo, filme e fotografias como documento de pesquisa. In. BAUER, Martin W.; GASKELL, George. Pesquisa qualitativa com texto, imagem e som: um manual prático. 7a ed. Petrópolis, RJ: Vozes, 2008.

MANNHEIM, Karl. Beiträge zur Theorie der Weltanschaungsinterpretation. Wissenssoziologie. Neuwied, Luchterhand, 1964, p. 91-154 [inglês: Essays on the sociology of Knowledge. London, Routledge + Kegan Paul, 1952, pp. 33-83].

MANNHEIM, Karl. Strukturen des Denkens. Frankfurt/M., Suhrkamp, 1980 [inglês: Structures of thinking. Collected Works Volume Ten. London: Routledge + Kegan Paul, 1982].

MAUAD, Ana Maria. O olhar engajado: fotografia contemporânea e as dimensões políticas da cultura visual. ArtCultura: Revista de História, Cultura e Arte, v. 10, n. 16, janeiro/junho de 2008. Disponível em: < http://www.artcultura.ppghis.inhis. ufu.br/viewarticle.php?id=227>. Acesso em 16 de novembro de 2009.

MENESES, Ulpiano T. Bezerra de. Fontes visuais, cultura visual, história visual: balanço provisório, propostas cautelares. Revista Brasileira de História. São Paulo, v. 23, n. 45, Julho de 2003. Disponível em: <http://www.scielo.br/scielo. php?script $=$ sci_arttext\&pid=S0102-01882003000100002\&lng $=$ en \&nrm $=$ iso $>$. Acesso em: 21 de novembro de 2009.

MICHEL, Burkard, Fotographien und ihre Lesarten. Dokumentarische Interpretation von Bildrezeptionsprozessen. In: BOHNSACK, Ralf; NOHL, Arnd-Michael; NENTWIG-GESEMANN, Iris (Orgs.). Die Dokumentarische Methode und ihrer Forschungspraxis. Opladen: Leske + Budrich, 2001. p. 91-120. 
MICHEL, Burkard, Fotographien und ihre Lesarten. Dokumentarische Interpretation von Bildrezeptionsprozessen. In: FRIEBERTSHÄUSER, Barbara; FELDEN, Heide; SCHÄFFER, Burkhard (Orgs.).Bild und Text. Methoden und Methodologien visueller Sozialforschung in der Erziehungswissenchaft. Opladen: Barbara Budrich, 2007. p. 61-78.

NOVAES, Sylvia Caiuby. Imagem, magia e imaginação: desafios ao texto antropológico. Mana, Rio de Janeiro, v. 14, n. 2, outubro de 2008. Disponível em: <http://www.scielo.br/scielo.php?script=sci_arttext\&pid=S010493132008000200007\&lng=en\&nrm =isso >. Acesso em: $0 \overline{2}$ de dezembro 2009.

PENN, Gema. Análise semiótica de imagens paradas. In. BAUER, Martin W.; GASKELL, George. Pesquisa qualitativa com texto, imagem e som: um manual prático. 7a ed. Petrópolis, RJ: Vozes, 2008.

SAMPAIO-RALHA, Jurema L. de F. Espaço Virtual e Educação em Arte. Revista Digital Art\&. São Paulo, ano IV, n. 05, abril de 2006.

SANTOS, Maria Madalen; GUEDES, Nadja Lisboa da Silveira. A Teoria da Perspectiva fundamentada pela geometria projetiva. In: VII International Conference on Graphics Engineering for Arts and Design, 2007, Curitiba. GRAPHICA. Curitiba: UFPR, 2007. Disponível em: < http://www.degraf.ufpr.br/artigos_graphica/>. Acesso em 16 de novembro de 2009.

WELLER, Wivian et al. Karl Mannheim e o método documentário de interpretação: uma forma de análise das visões de mundo. Sociedade e Estado, Brasília, v. 17, n. 2, p. 375-396, jul./dez. 2002.

WELLER, Wivian. A contribuição de Karl Mannheim para a pesquisa qualitativa: aspectos teóricos e metodológicos. Sociologias, Porto Alegre, ano 7, n. 13, p. 260-300, jan./jun. 2005.

Recebido em: 18/05/2011

Aceite final: 13/07/2011 